\title{
Context-dependency of cue-elicited urge to smoke
}

\author{
Citation for published version (APA):
}

Thewissen, R., van den Hout, M. A., Havermans, R. C., \& Jansen, A. T. M. (2005). Context-dependency of cue-elicited urge to smoke. Addiction, 100, 387-396. https://doi.org/10.1111/j.1360-0443.2005.00996.x

Document status and date:

Published: 01/01/2005

DOI:

10.1111/j.1360-0443.2005.00996.x

Document Version:

Publisher's PDF, also known as Version of record

Document license:
Taverne

\section{Please check the document version of this publication:}

- A submitted manuscript is the version of the article upon submission and before peer-review. There can be important differences between the submitted version and the official published version of record.

People interested in the research are advised to contact the author for the final version of the publication, or visit the DOI to the publisher's website.

- The final author version and the galley proof are versions of the publication after peer review.

- The final published version features the final layout of the paper including the volume, issue and page numbers.

Link to publication

\footnotetext{
General rights rights.

- You may freely distribute the URL identifying the publication in the public portal. please follow below link for the End User Agreement:

www.umlib.nl/taverne-license

Take down policy

If you believe that this document breaches copyright please contact us at:

repository@maastrichtuniversity.nl

providing details and we will investigate your claim.
}

Copyright and moral rights for the publications made accessible in the public portal are retained by the authors and/or other copyright owners and it is a condition of accessing publications that users recognise and abide by the legal requirements associated with these

- Users may download and print one copy of any publication from the public portal for the purpose of private study or research.

- You may not further distribute the material or use it for any profit-making activity or commercial gain

If the publication is distributed under the terms of Article $25 \mathrm{fa}$ of the Dutch Copyright Act, indicated by the "Taverne" license above, 


\title{
Context-dependency of cue-elicited urge to smoke
}

\author{
Roy Thewissen ${ }^{1,2}$, Marcel van den Hout ${ }^{3}$, Remco C. Havermans ${ }^{2}$ \& Anita Jansen ${ }^{2}$ \\ Department of Medical, Clinical and Experimental Psychology,' Department of Experimental Psychology, Maastricht University, the Netherlands ${ }^{2}$ and Department
} of Clinical Psychology, Utrecht University, the Netherlands ${ }^{3}$

Correspondence to:

Roy Thewissen

Maastricht University

Faculty of Psychology

Department of Medical

Clinical and Experimental Psychology and

Department of Experimental Psychology

PO Box 616

$6200 \mathrm{MD}$

Maastricht

the Netherlands

Tel: +31433882476

E-mail: r.thewissen@psychology.unimaas.nl

Submitted 23 February 2004;

initial review completed 14 May 2004;

final version accepted 15 November 2004

\section{ABSTRACT}

Aims Earlier studies have suggested that the cue-induced urge to smoke depends on the expectation of the availability of smoking. The present study investigated whether a 'room context' change could undo the learned discrimination between two stimuli, respectively, predicting smoking availability or smoking unavailability.

Design A 2 (smoking cue) $\times 2$ (availability context cue) $\times 6$ (trial) $\times 2$ (room context change) within-subjects design was used. Participants were repeatedly presented with a context cue predicting smoking availability (blue serving tray) and a context cue predicting unavailability (yellow serving tray) in one room and tested for an effect of context change in a different room.

Setting Two distinct rooms located in different department buildings of Maastricht University.

Participants Seventeen daily smokers who had smoked at least five cigarettes a day for at least 2 years.

Measurements Self-reported urge to smoke using a visual analogue scale (VAS).

Findings and conclusions Results replicated the finding that a context cue that predicted smoking elicited greater urges to smoke than a context cue that predicted no smoking, irrespective of the presence of smoking cues. In addition, this study showed that this differential effect on the urge to smoke was generalized to a context other than the context in which learning took place. These findings are discussed in relation to the significance of a context change regarding the predictive value of smoking availability.

KEYWORDS Conditioning, context, cue exposure, expectancy, smoking availability, urge to smoke.

\section{INTRODUCTION}

In general, the urge to use a drug is conceptualized as an emotional state in which the individual is motivated to seek and use the drug (see Baker et al. 1987; Tiffany 1990; Drummond et al. 2000). There is considerable interest in the urge (or craving) phenomenon from a theoretical and clinical perspective, as drug urges play an important role in the maintenance and relapse of addictive behaviour (Drummond et al. 2000). The cue-reactivity paradigm has proved useful in studying the relevance of urges in explaining maintenance and relapse of drug use (see, e.g. Niaura et al. 1988; Drummond, Cooper \&
Glautier 1990; Drummond 2000). The theory of Pavlovian conditioning suggests that stimuli or cues (conditioned stimuli, CS) can be associated with drug intake (e.g. smoking behaviour) (unconditioned stimuli, US) and as a result these cues will elicit conditioned responses (CRs), or cue-reactivity (physiological and psychological). These conditioned responses can be experienced subjectively as an urge to use a given drug (Lavez et al. 1999) (for a critical discussion about the nature of these conditioned responses, see Niaura et al. 1988; Carter \& Tiffany 1999).

Clinical implications derived from this theoretical position led to the application of an exposure-based treat- 
ment for addiction, comparable with the treatment of anxiety disorders (e.g. Lee, \& Oei 1993). Cue exposure with response prevention is a therapeutic strategy designed especially to deal with the aspect of urge. For example, a smoker is exposed repeatedly to smoking cues (e.g. cigarettes, lighters, ashtrays), but is not allowed to smoke (response prevention). This procedure then should lead to the elimination of the previously learned association between smoking cues and smoking. As a result, the smoking cue-reactivity should be extinguished at the end of the treatment. Furthermore, by eliminating an important motivation for continued drug use the probability of a (re)lapse should be limited. Cue exposure therapy has been used extensively in the clinical domain and research into its effectiveness has shown that it can indeed lead to the extinction of drug urges (see, e.g. O'Brien et al. 1990; Monti et al. 1993; Powell et al. 1993; Drummond \& Glautier 1994; Franken et al. 1999; Niaura et al. 1999). However, relapse after 'successful' treatment is still a matter of great concern for clinicians and their clients and cue exposure does not tend to reduce relapse rates (Conklin \& Tiffany 2002; Havermans \& Jansen 2003).

Contemporary learning theory provides an explanation for the apparent limited effectiveness of cue exposure therapy. Bouton and colleagues (Bouton \& Bolles 1979; Bouton 1988, 2000; Bouton \& Swartzentruber 1991) have shown repeatedly that extinction does not entail the 'unlearning' of the CS-US association, but instead the learning of a new inhibitory association (CS-no US). This newly learned association during extinction is controlled by the context in which the extinction treatment took place. The client learns that, given the extinction context, the US will no longer follow the CS. As a consequence, an extinguished CR is renewed when the client is exposed to the CS outside the extinction context. In other words, cue-elicited urges can be extinguished, but when the client is exposed to drug-related cues outside the environment in which exposure took place these urges may reappear, rendering cue exposure therapy ineffective (Conklin \& Tiffany 2002; Havermans \& Jansen 2003). Indeed, some evidence for such a renewal of drug cuereactivity after cue exposure treatment has been found in social drinkers (Collins \& Brandon 2002; but see Staiger et al. 1999).

The renewal of extinguished cue-reactivity demonstrates the importance of contextual variables in cueelicited responding. Contexts appear to control the meaning of more punctuated cues; that is, drug cues predict drug use within the drug use environment, but predict the absence of drug-taking behaviour in a treatment setting. Translating this notion to addiction to smoking, Dols et al. (2000) investigated the influence of context on cue-elicited urge to smoke. Smokers were exposed to two contexts: one context (signalled by a yellow card) pre- dicted no smoking and the other context (signalled by a blue card) predicted smoking. In each context, the urge to smoke was rated before and after the presentation of smoking cues (favourite brand of cigarettes, ashtray and lighter). Results showed that smoking cues elicited less urge in the non-smoking context than in the smoking context. In addition, the contexts appeared better predictors of smoking or non-smoking than the smoking cues. Germane smoking cues elicited a stronger urge to smoke when presented in the smoking context than when presented in the non-smoking context. This study was replicated under more stringent conditions and the results were essentially similar (see Dols et al. 2002). It was concluded that smoking cues elicit urges due mainly to the expectation of smoking or non-smoking and due less to a long history of associative learning. The perceived availability of smoking seems to be more crucial for eliciting the urge to smoke (e.g. Droungas et al. 1995; Powell 1995; Juliano \& Brandon 1998; Carter \& Tiffany 2001). Recently, a review of the collected studies (so far) that directly or indirectly addressed drug availability consistently reported stronger self-reported urges when clients perceive their drug available for use than when not (Wertz \& Sayette 2001).

Dols et al. (2000, 2002) showed that the cue-induced urge to smoke could be influenced by manipulating the expectation of smoking. This experiment was designed to investigate whether the learned control over cue-elicited urges by context cues (i.e. blue versus yellow card) generalizes across more naturalistic environmental contexts. If so, it could be argued that the experimental manipulation of the expectation of smoking provides a potentially effective alternative to cue exposure treatment of smoking dependency.

The experimental procedure used in this experiment was similar to the procedure used by Dols and colleagues $(2000,2002)$ and is a discriminative classical conditioning task in which 'cue-availability' (Carter \& Tiffany 2001) or 'perceived drug use opportunity' (Wertz \& Sayette 2001) is manipulated. This design was implemented in a more naturalistic environmental context to investigate the influence of a particular setting on the learned expectations regarding the availability of smoking. That is, the aim was to examine whether a context change from one room to a new room would undo the learned discrimination between two stimuli predicting smoking or no smoking, respectively. In this study, three types of stimuli were presented: smoking cues (favourite brand of cigarettes, lighter and ashtray; SC), context cues (blue or yellow serving trays; $\mathrm{CC}$ ), and two different rooms that served as the naturalistic environmental contexts. The smoking cues were stimuli presumed to elicit conditioned craving responses as a result of smoking history. The coloured serving trays served as context cues explicitly 
signalling smoking availability; that is to say, in the blue situation the presentation of the smoking cues would be followed by smoking (taking one puff), whereas in the yellow situation the presentation of the smoking cues would not be followed by smoking (smoking is not allowed). The rooms may be seen as more incidental contextual variables in which the experimental manipulation is embedded. The physical elements or characteristics of the rooms referred to a distinct semantic whole, categorized as an 'office' and a 'therapy room'. However, these two rooms were equivalent in terms of their limited smokingrelevant characteristics; that is, participants were likely to evaluate these rooms as places where they would not expect to be allowed to smoke, which did not remind them of places where they have smoked before (reference to a smoking context), in which they experienced low levels of the urge to smoke, in which they were able to refuse a cigarette (control of smoking), in which they felt positive or pleasant (valence of the room) and in which they were relaxed (subjective arousal). These data were derived from an unpublished pilot study $(n=22)$ in which five different rooms were evaluated by smokers on the above characteristics.

Similar to the procedure of Dols and colleagues (2000, 2002), smokers were exposed to their smoking cues in either an availability or an unavailability context (signalled by a blue versus a yellow serving tray). After this, smokers were tested in the same room and in a different room. As in the two previous studies by Dols and colleagues $(2000,2002)$, it was expected that (a) the context cue (i.e. serving tray) associated with smoking (US) would come to function as a conditioned stimulus (CS+) predicting the occurrence of smoking, hence eliciting a conditioned urge response, whereas the other context cue not associated with smoking (no US) would come to function as a conditioned inhibitory stimulus (CS-) predicting smoking abstinence, hence extinguishing or diminishing conditioned urge responding; (b) urge responses would be stronger when smoking cues were presented than when not, irrespective of the context cue; (c) urge responses to the smoking cues would be stronger if the 'availability context cue' was given than if the 'unavailability context cue' was given; (d) after a room context change the difference in conditioned urge response between the 'unavailability context cue' and the 'availability context cue' would be reduced (loss of generalization).

\section{METHOD}

\section{Participants}

Seventeen smokers (10 females, seven males; M age $=23.8$ years, $\mathrm{SD}=4.9$ ) participated in the present study. All but three participants (two males and one female) were students at Maastricht University and responded to posted advertisements. All participants had been smoking for at least 2 years, with a minimum of five cigarettes a day. The average score on the revised Fagerström Test for Nicotine Dependence (FTND; Heatherton et al. 1991) was $2.9(\mathrm{SD}=2.5)$. Participants were not allowed to smoke for 2 hours prior to the experiment. An abstinent period of 2 hours was chosen to ensure that the desire to smoke would not be too low or too high, preventing a floor and ceiling effect of urge during the conditioning task.

\section{Setting}

The experiment took place in two especially designed rooms at Maastricht University. Both rooms were made distinctive in their physical characteristics. One room was arranged as a typical office with two desks, two computers, office materials (e.g. pens, papers, phones and covers), a red carpet and red office chairs, and had a window. The other room was a therapy setting with a desk, books, plants and 'nature' posters, a flip-over and blue chairs, which had no window. The two rooms were located in two different department buildings on the university campus. Additionally, the rooms were made distinctive by spreading two different odours ('Vanilla \& Lily' and 'After Tobacco air'; Ambi Pur, Veenendaal/the Netherlands). Both rooms had an exhaust tube connected to a ventilator in the ceiling to remove smoke instantly, although the tubes were of different material and colour.

\section{Measures}

Pre-acquisition phase

A 100-mm visual analogue scale (VAS) was used to measure the valence of the room (question: 'In this room, I feel', range: 0 'very unpleasant/negative'-100 'very pleasant/positive'); subjective arousal (question: 'At this moment, I feel', range: 0 'very relaxed'-100 'very tense'); urge to smoke (question: 'At this moment, I feel', range: 0 'no urge to smoke at all'-100 'an almost irresistible urge to smoke'); reference to a smoking context (question: 'This room makes me think of a room in which I smoked', range: 0 'very little to not at all'-100 'very much'); perceived control of smoking (question: 'If at this moment I were offered a cigarette, I would be able to refuse', range: 0 'definitely not'-100 'definitely'); and expectation of availability to smoke (question: 'In this room I expect to be allowed to smoke', range: 0 'definitely not'-100 'definitely'). Another VAS was used to measure the extent to which participants evaluated the two rooms as being different (question: 'The first room differs from the second 
room', range: 0 'to a small extent'-100 'to a large extent').

\section{Acquisition and test phase}

A VAS was used to measure urge to smoke (question: 'At this moment, I feel', range: 0 'No urge to smoke at all'100 'a nearly irresistible urge to smoke').

\section{Postexperimental questionnaire}

Four VASs were used retrospectively to measure preexperimental expectations about the participants' urge to smoke when presented with the serving trays and the smoking cues (question: 'To what extent-prior to the experiment-did you expect that your urge to smoke would increase, decrease or stay at the same level when presented with the yellow (or blue) serving tray', range: 0 'decrease', 50-'same level', 100 'increase'); (question: 'To what extent-prior to the experiment-did you expect that your urge to smoke would increase, decrease or stay at the same level, when presented with the yellow (or blue) serving tray and the cigarettes, lighter and ashtray', range: 0 'decrease', 50-'same level', 100 'increase').

\section{Procedure}

Participants were asked to refrain from smoking for 2 hours prior to the experiment. On arrival, participants received an introduction to the study and completed an informed consent form in the waiting room. After the introduction their expired air carbon monoxide [CO in parts per million (p.p.m.)] content was measured and they completed the FTND questionnaire. Next, they were guided to two rooms for a pre-acquisition session. They were instructed to relax for 1 minute and to pay attention to the features of the room and to note what they felt and experienced at that moment. Then they completed a VAS questionnaire in which they rated 'expectation of availability to smoke'; 'reference to a smoking context'; 'urge to smoke'; 'control of smoking'; 'valence of the room'; and 'subjective arousal'. After a 5-minute break the same was conducted for the other room. Another VAS was used to measure the extent to which participants evaluated the two rooms as being different. Again after a short break of 3 minutes participants were taken to the room where the acquisition phase would take place.

The procedure for the acquisition phase was modelled after the study by Dols et al. (2002). At the start of the acquisition phase, participants were explicitly informed about the meaning of the blue and yellow situation in which they would be exposed to their smoking cues. Seated at a table, participants were then presented with the serving tray (blue or yellow) and instructed to pay attention to the colour of the serving tray and to note their feelings and thoughts during that time. After approximately 30 seconds the experimenter presented the participant with a VAS on which s/he was instructed to rate his/her urge to smoke. Then the participant was exposed to smoking cues (favourite brand of cigarettes, ashtray and lighter). The participant was instructed to handle the cues for approximately 30 seconds. The participant was instructed to touch the cigarette, smell it, place it between the lips (without being allowed to sham smoke) and hold a burning lighter near the cigarette (without being allowed to light it). Then the second VAS assessment of urge took place, followed by the occurrence or non-occurrence of smoking. If the participants were allowed to smoke, they were instructed to take one puff and exhale the smoke through a respiratory tube, followed by a reading break. In the unavailability situation participants were instructed to take the cigarette between their lips and hold a burning lighter to the cigarette, but were not allowed to light it and smoke. This was also followed by a reading break. Each participant was put into six smoking and unavailability situations that were presented in a pseudo-random order, with no more than three of the same types of situation in succession. The duration of the reading break between trials for both situations was approximately 3 minutes. The total duration of the acquisition phase was approximately 60 minutes.

The testing phase took place after a 5-minute break, in the same or the other room. There the participants were again presented with both situations (blue and yellow serving tray; one trial each, order counterbalanced between participants) and completed the urge VAS, followed by additional exposure to the smoking cues and again the urge VAS. After a 5-minute break participants were again tested in the other room in a similar manner. At the end of the experiment, participants filled in a postexperimental questionnaire and were debriefed.

\section{RESULTS}

\section{Data reduction and analyses}

Results will be reported for the three main phases of the experiment: pre-acquisition, acquisition and test. During the pre-acquisition phase 'perceived expectation of availability to smoke'; 'reference to a smoking context'; 'urge to smoke'; 'control of smoking'; 'valence of the room'; and 'subjective arousal' were rated on a 100-mm VAS. This was performed for the two rooms: the 'office' and the 'therapy room'. In addition, a 100-mm VAS was used to measure the extent to which participants felt the two rooms to be different. To test a potential context change effect, the rooms used in this experiment had to be phys- 
ically different but equivalent in terms of their smokingrelevant characteristics. That is, both contexts had to produce the same response pattern for all these measures. Paired-sample $t$-tests were used to test this hypothesis.

During acquisition and testing, every presentation of the coloured serving tray (context cue) and every presentation of the smoking cues (cue) was followed by a VAS (urge to smoke). During the acquisition phase, there were six trials of each context cue (yellow and blue serving tray) and during every trial context cues were presented alone and with smoking cues. Thus during acquisition there were 24 measurements of urge to smoke. A $2 \times 2 \times 6$ (smoking cue $\times$ context cue $\times$ trial) repeatedmeasures analysis of variance (ANOVA) was performed for the acquisition phase with the self-reported urge to smoke. During the test phase, each context cue was presented alone and with smoking cues. Thus the urge was measured four times during the test. For the test phase a $2 \times 2 \times 2($ context change $\times$ context cue $\times$ smoking cue $)$ repeated-measures ANOVA was conducted.

The postexperimental questionnaire, using VASs, retrospectively measured pre-experimental expectations about the urge to smoke when presented with serving trays and smoking cues. Paired-sample $t$-tests were used to test differences.

\section{Pre-acquisition}

Table 1 displays mean scores for the two contexts on all the indices. There were no significant differences measured between 'office' context and 'therapy-room' context on all the indices $(-1.04<t<1.01 ; P>0.32)$. However, participants did evaluate these rooms as being perceptually distinct, which is demonstrated by the average score on the VAS measure 'difference between rooms' $(\mathrm{M}=62.4 ; \mathrm{SD}=21.1 ; t=12.23 ; \mathrm{df}=16 ; P<0.01)$. Thus, the 'office' context and the 'therapy-room' context were equivalent in terms of their limited smoking-relevant characteristics, yet distinct in terms of their physical characteristics.

\section{Acquisition}

Hypothesis (a): urges to smoke are stronger if the availability context cue is given than if the unavailability context cue is given

The mean urges to smoke scores in all four conditions as measured during the acquisition phase are shown in Table 2. The effects of context cues and smoking cues on urge to smoke during the acquisition phase are depicted in Fig. 1. As predicted, participants who expected smoking to occur after exposure reported a stronger urge compared to participants who expected that smoking would not occur. This was revealed by a significant main effect of context cue $\left(F_{1,16}=10.47 ; P<0.01\right)$. In general, smokers experienced higher levels of urge when exposed to a context cue that predicted smoking than when exposed to a context cue that predicted no smoking. Thus, the context cues acquired the capacity to differentially elicit urge responding.

Hypothesis (b): urges to smoke are stronger when smoking cues are presented than when not, irrespective of the context cues

A significant main effect of smoking cues confirmed the hypothesis that participants report stronger urges when exposed to their smoking cues than when not, irrespective of the context cues $\left(F_{1,16}=8.21 ; P<0.05\right)$. As depicted in Fig. 1, the lines representing the presence of smoking cues $(\mathrm{SC}+)$ are higher than the lines represent-

Table 1 Mean scores on smoking-related measures for the two contexts/rooms.

\begin{tabular}{lllllll}
\hline & $\begin{array}{l}\text { Arousal } \\
M(S D)\end{array}$ & $\begin{array}{l}\text { Valence } \\
M(S D)\end{array}$ & $\begin{array}{l}\text { Urge } \\
M(S D)\end{array}$ & $\begin{array}{l}\text { Reference } \\
M(S D)\end{array}$ & $\begin{array}{l}\text { Control } \\
M(S D)\end{array}$ & $\begin{array}{l}\text { Expectancy } \\
M(S D)\end{array}$ \\
\hline $\begin{array}{llllll}\text { 'The office' } \\
\text { 'The therapy room' }\end{array}$ & $34.0(19.1)$ & $55.2(20.7)$ & $34.5(16.7)$ & $36.7(30.2)$ & $58.8(28.1)$ & $32.5(25.1)$ \\
& $32.4(15.5)$ & $62.9(15.6)$ & $30.5(18.1)$ & $26.1(25.2)$ & $61.8(28.4)$ & $33.7(28.6)$ \\
\hline
\end{tabular}

Table 2 Mean urge to smoke scores in all four conditions $(n=17)$ in blocks of two trials (blocks $1-3)$ of the acquisition phase.

\begin{tabular}{llllr}
\hline & $\begin{array}{l}C-/ S C- \\
M(S D)\end{array}$ & $\begin{array}{l}C C-/ S C+ \\
M(S D)\end{array}$ & $\begin{array}{l}C C+/ S C- \\
M(S D)\end{array}$ & $\begin{array}{l}C C+/ S C+ \\
M(S D)\end{array}$ \\
\hline Block 1 & $43.4(21.0)$ & $50.1(22.2)$ & $50.2(18.4)$ & $55.2(19.1)$ \\
Block 2 & $40.7(22.0)$ & $46.9(19.6)$ & $47.4(25.4)$ & $51.4(24.0)$ \\
Block 3 & $38.8(23.2)$ & $40.0(21.4)$ & $44.1(24.9)$ & $47.4(24.2)$
\end{tabular}

$(\mathrm{CC}-)=$ unavailability context cue; $(\mathrm{CC}+)=$ availability context cue; $(\mathrm{SC}-)=$ smoking cues absent; $(\mathrm{SC}+)=$ smoking cues present . 


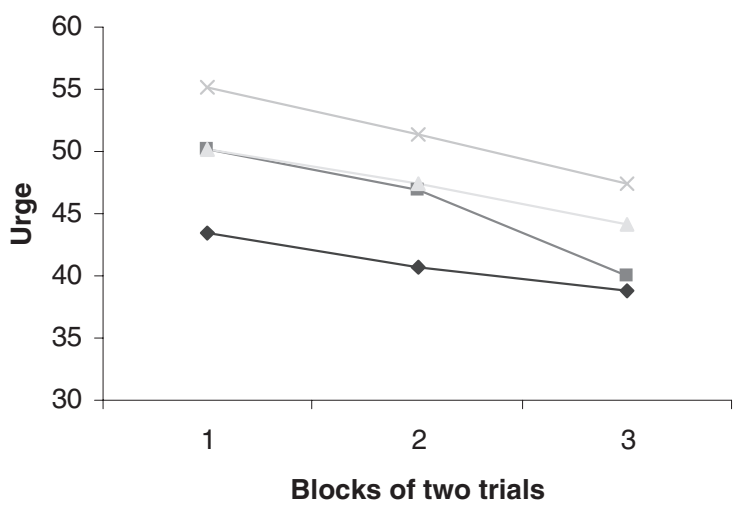

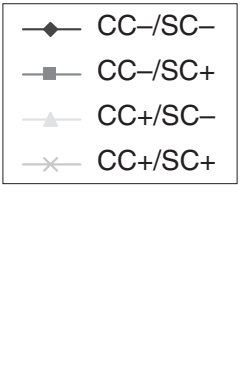

Figure I Effects of context cues and smoking cues during the acquisition phase. $(\mathrm{CC}-)$ = unavailability context cue; $(\mathrm{CC}+)=$ availability context cue; (SC-)= smoking cues absent; $(\mathrm{SC}+)=$ smoking cues present

Table 3 Mean urge to smoke scores in all four conditions $(n=17)$ during the test phase.

\begin{tabular}{lllll}
\hline Context change & $C C-/ S C-$ & $C C-/ S C+$ & $C C+/ S C-$ & $C C+/ S C+$ \\
$M(S D)$ & $M(S D)$ & $M(S D)$ & $37.9(25.5)$ \\
\hline Yes & $M(S D)$ & $30.1(26.1)$ & $39.2(23.7)$ & $43.2(24.0)$ \\
No & $29.6(25.5)$ & $37.7(26.2)$ & & $37.25)$ \\
\hline
\end{tabular}

$(\mathrm{CC}-)=$ unavailability context cue; $(\mathrm{CC}+)=$ availability context cue; $(\mathrm{SC}-)=$ smoking cues absent; $(\mathrm{SC}+)=$ smoking cues present.

ing the absence of smoking cues (SC-) on all three trials, with the exception of $\mathrm{CC}-/ \mathrm{SC}+$ on trial 3.

Hypothesis (c): urges to smoke in response to smoking cues are stronger if the availability context cue is given than if the unavailability context cue is given

The prediction that urge responding to the smoking cues should be stronger if the availability context cue is given than if the unavailability context cue is given could not be confirmed by a significant context cues smoking cues interaction $\left(F_{1,16}=0.18 ; P=0.69\right)$. Thus, the urge-inducing effects of the smoking cues were the same for both context cues.

\section{Effect of the trial}

An overall effect of the trial was found, indicating a significant decrease of urge over trials for all four conditions (lines) in Fig. $1\left(F_{5,80}=3.14 ; P<0.05\right)$. More specifically, results showed a significant smoking cues-trial interaction $\left(F_{5,80}=4.35 ; P<0.01\right)$. No significant context cue $\times$ smoking cue trial interaction was revealed $\left(F_{5,80}=0.74 ; P>0.59\right)$. To examine this interaction further, separate post hoc tests were conducted with trial as the independent variable and urge responding in the presence or absence of smoking cues as the dependent variable, using a Bonferroni-corrected rejection criterion of $\alpha=0.025$. Urge responding to the presence of the smoking cues decreased significantly from the first to the last trial $\left(F_{5,80}=5.77 ; P<0.01\right)$, whereas urge responding to the absence of the smoking cues remained the same from the first to the last trial $\left(F_{5.80}=1.20 ; P>0.30\right)$. This suggests an overall extinction of urge responding when participants are repeatedly exposed to their smoking cues.

\section{Test}

The results of the acquisition phase showed differential learning in the case of the context cues. That is, the availability context cue that confirmed the association between smoking cues and smoking behaviour elicited an urge response, whereas the unavailability context cue that weakened the association between smoking cues and smoking behaviour became a conditioned stimulus inhibiting urge responding. The data therefore allowed a test for hypothesis (d).

Hypothesis (d): after a room context change the difference in conditioned urge response between the "unavailability context cue' and the 'availability context cue' will be reduced (loss of generalization)

The mean urges to smoke scores in all four conditions as measured during the test phase are shown in Table 3. The effects of context cues and smoking cues on the urge to smoke during the test phase are shown in Fig. 2. A significant main effect of context cue was found $\left(F_{1,16}=7.87\right.$; $P<0.05)$ indicating a higher urge score for the availability context cue than for the unavailability context cue. As can be seen in Fig. 2, the lines representing the condition of the availability context cue $(\mathrm{CC}+)$ are higher than the lines representing the condition of the unavailability con- 
Figure 2 Effects of context change on context cues and smoking cues during the test phase. $(C C-)=$ unavailability context cue; $(C C+)=$ availability context cue; $(\mathrm{SC}-)=$ smoking cues absent; $(\mathrm{SC}+)=$ smoking cues present

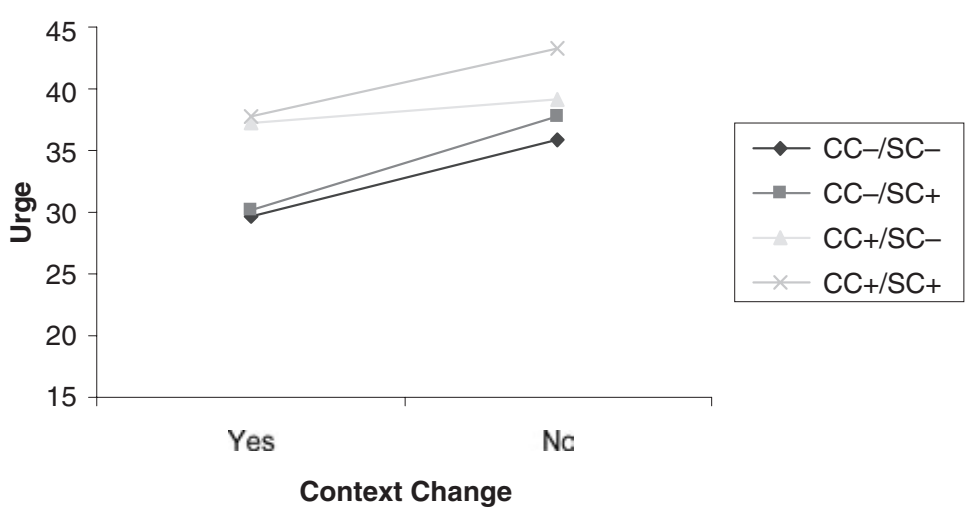

the availability context cue that predicts smoking was given, the smoking cues elicited an additional urge to smoke in comparison with the unavailability context cue that predicted no smoking. This interaction was observed only in the group that did not receive a belief neutralization manipulation (by reading a statement at the beginning of the experiment informing the subjects that research has found contradicting results with regard to the urge-eliciting capacity of smoking contexts and nonsmoking contexts). The authors suggested that this difference was due to a demand effect; that is, participants could have held pre-experimental expectations of what the outcome of the study should be. In the present study no belief neutralization was conducted. Therefore it is suggested that there was a general expectation that smoking cues would elicit an urge to smoke regardless of a given context cue. A postexperimental check (the questions asked referred to pre-experimental expectations) of expectations revealed that participants did have a significantly higher expectation that the addition of the smoking cues would increase their levels of urge in comparison with the mere presentation of the context cues (serving trays), both in case of the unavailability context cue and the availability context cue being given. Thus, these preexperimental expectations could generally have generated the stronger urge scores after presentation of the smoking cues, irrespective of the given context cues. Nevertheless, the context cues that were not associated previously with smoking immediately acquired the potential of elicited differential conditioned urge response depending on their predictive value for smoking. The smoking expectancy, in this case signalled by environmental cues (coloured serving trays), seems to be crucial for these cues to acquire the ability to control urge reactivity. This finding is in line with the growing body of literature on the effect of perceived drug use availability on the capacity of drug-related cues to elicit the urge to use (for a review see Wertz \& Sayette 2001). For example, Carter \& Tiffany (2001) repeatedly exposed smokers to either a lit cigarette in an ashtray or a glass of water. On each trial participants were informed about the probability $(0 \%$, 
$50 \%$ or $100 \%$ ) of being able to either take a puff of the cigarette or take a sip of the water. In this way they manipulated cigarette availability and found that urge ratings increased on cigarette trials with increased availability to smoke, whereas no effect was observed on urge with increased availability on the water trials.

One could argue that the present results are the result of experimental demand as the participants were instructed beforehand about the predictive value of the coloured serving trays instead of learning these contingencies through experience. In other words, participants would behave according to received instructions rather than demonstrate conditioned urge responding. However, the participants were not informed explicitly about the specific hypotheses regarding urge responding and thus can be said to behave according to the acquired contingencies between the coloured trays and smoking availability. Contemporary human learning research has repeatedly demonstrated that conditioned responding (both subjective and psychophysiological responding) is based on such acquired associations and that these associations can be acquired through both instructions and trial-by-trial experience (see for instance Dawson \& Schell 1987; Davey 1992; Lovibond 2003). Furthermore, by giving information about the CS-US contingency before the conditioning task, conscious awareness of this association is raised and therefore conditioning effects could be facilitated, as suggested and studied by Dawson and colleagues (e.g. Dawson 1973; Dawson \& Schell 1987; see also Field \& Duka 2001 for an application of these principles in a discriminative classical conditioning task with smokers). As such, the urge responses elicited by the coloured serving trays can be described as conditioned urge responding. Note that the issue of possible experimental demand in an experimental preparation of the present type addressed was explicitly and empirically by Dols et al. (2002). Dols et al. (2002) controlled for this effect by conducting a belief-neutralization procedure for half the subjects prior to participation in the experiment (by reading a statement at the beginning of the experiment informing the subjects that research has found contradicting results with regard to the urge-eliciting capacity of smoking contexts and non-smoking contexts). A postexperimental questionnaire tested the effect of the belief neutralization on personal and research beliefs regarding effect of cues and context on urge to smoke. No differences were found on personal and research beliefs except for the non-smoking context without smoking cues condition (CC-/SC-). The expected urge to smoke was significantly lower than all the other conditions of the researcher's beliefs. If only the CC-/SCcondition differed in the belief neutralization group, this difference would have an effect on the depended variable urge to smoke, and thus the two groups would have dif- fered on urge scores in the CC-/SC- condition. Despite the fact that the group differed in expectation, there was no effect on urge scores in the CC-/SC- condition between the two groups, indicating that experimental demand was minimal. Furthermore, they found that this procedure did not fundamentally affect results; that is, irrespective of belief-neutralization participants reported stronger urges when exposed to the availability context cue than when exposed to the unavailability context cue. In other words, beliefs about the outcome of the experiment did not appear to affect results at all. As the present experimental procedure is similar to the procedure used by Dols et al. (2002) it is unlikely that experimental demand effects have played an important role in the present findings.

The present results showed further that changing room contexts did not lead to the reduction of differential urge responding controlled by the availability and the unavailability context cue. Urge responses were stronger if the availability context cue was given than if the unavailability context cue was given and this generalized to a room context different from the context in which the acquisition phase took place. It could be argued that the context change in the present study was hardly a challenge, as both rooms differed only in their physical characteristics and not in their smoking-relevant characteristics. It is feasible that a context change has to be of sufficient significance with regard to the prediction of smoking availability, in other words the prediction of the occurrence of smoking (i.e. US), before context can modulate previous learned expectancies. The context change therefore has to be meaningful in relation to the availability of smoking. For example, changing the context from a 'low smoking-relevant' to a 'high smokingrelevant' context (for instance a bar) could be meaningful enough to alter the expectancy relation of the context cues and/or smoking cues, hence causing a reduction of differential conditioned urge responding between the context cues. This would demonstrate that there is a more complex relationship between cues, context cues and broader contexts in the human classical conditioning phenomenon. Whether the generalization of learned differential urge responding across environmental contexts depends on the relevance for smoking of the contexts requires further research.

The finding that the urge to smoke can be controlled by expectations regarding the occurrence of smoking provides support for a cognitive perspective on cue exposure treatment. As Dols et al. (2002) proposed, smokers can learn to control or even master their urge to smoke by controlling their expectancies regarding smoking. Therapists, using a similar procedure to Dols and colleagues (2000, 2002), can teach smokers that their urge to smoke is not an uncontrollable phenomenon, triggered 
by environmental stimuli, but is something that depends (partly) on their own expectations regarding the occurrence of smoking. Smokers who take the decision to quit smoking but are confronted with strong levels of urge can hold ineffective beliefs and ideas concerning the consequences of their urge experiences. They could, for instance, hold the belief that urge automatically has to lead to smoking; that one loses control over smoking behaviour; that one goes mad if one does not smoke; etc. Although a wide range of cues, context cues, contexts and the urge itself can lead to high levels of urge, cue exposure can be taken as a (final) behavioural experiment, during which the client can discover and experience that urge does not have to lead to smoking and that early cognitions (i.e. expectations, beliefs, etc.) can be modified. The results of this study, although preliminary, also point to the importance, for therapists and clients, of the role of the wider context in which cue exposure takes place, and this in relation to the smoking-related contexts outside the exposure context. The finding that no context change effect became apparent after changing room contexts - which are different in terms of their physical characteristics but are equivalent with regard to their low smoking-relevant characteristics-points to the possibility of generalizing learned expectations concerning smoking from these kinds of contexts. Although in this study participants were not attempting to quit and thus were not at risk of relapsing, an analogue can be drawn for determinants of maintaining drug use behaviour. Following Marlatt's (1985) theoretical framework of determinants of relapse, the two rooms/contexts used in this study can be defined as 'low-risk situations' as opposed to 'high-risk situations'. That is, these rooms/contexts possess a low risk for relapse because of their low smokingrelevant characteristics. It should be noted, however, that the present sample size was small and comprised mainly light smokers $(\mathrm{FTND}=2.9)$ who were not attempting to quit smoking at the time of testing, although the population of Dols et al. (2002) had an average FTND of 2.13 while smoking at least 10 cigarettes a day. Therefore, whether learning to control cue-elicited urges truly constitutes a valuable treatment component requires further empirical validation.

To recapitulate, this study replicated the main finding of context dependency of cue-elicited urge to smoke using a procedure similar to that of Dols and colleagues (2000, 2002). The expectancy of smoking availability increases urge responding in comparison with the expectation of smoking unavailability. Smokers can thus be taught to exert control over their urge by manipulating their expectancies regarding cue-elicited urge and smoking behaviour. This supports a more cognitive approach in deploying cue exposure strategies in the treatment of addiction. In addition, this study provides preliminary support for generalization of the effect of learned expectations of availability to smoke on the urge to smoke. As such, the present results warrant further research to examine the degree to which learning to control one's urge to smoke will be beneficial for the treatment of smoking addiction.

\section{Acknowledgements}

This research was supported by Grant 985-10-006 from NWO-ZON program.

\section{References}

Baker, T. B., Morse, E. \& Sherman, J. E. (1987) The motivation to use drugs: a psychobiological analysis of urges. In: Rivers, C., ed. The Nebraska Symposium on Motivation: Alcohol Use and Abuse, pp. 257-323. Lincoln: University of Nebraska Press.

Bouton, M. E. (1988) Context and ambiguity in the extinction of emotional learning: implications for exposure therapy. Behavior Research and Therapy, 26, 137-149.

Bouton, M. E. (2000) A learning theory perspective on lapse, relapse, and the maintenance of behavior change. Health Psychology, 19, 57-63.

Bouton, M. E. \& Bolles, R. C. (1979) Contextual control of the extinction of conditioned fear. Learning and Motivation, 10, 445-466.

Bouton, M. E. \& Swartzentruber, D. (1991) Sources of relapse after extinction in Pavlovian and instrumental learning. Clinical Psychology Review, 11, 123-140.

Carter, B. L. \& Tiffany, S. T. (1999) Meta-analysis of cue reactivity in addiction research. Addiction, 94, 327-340.

Carter, B. L. \& Tiffany, S. T. (2001) The cue-availability paradigm: the effects of cigarette availability on cue reactivity in smokers. Experimental and Clinical Psychopharmacology, 9, 183-190.

Collins, B. N. \& Brandon, T. H. (2002) Effects of extinction context and retrieval cues on alcohol cue reactivity among nonalcoholic drinkers. Journal of Consulting and Clinical Psychology, 70, 390-397.

Conklin, C. A. \& Tiffany, S. T. (2002) Applying extinction research and theory to cue-exposure addiction treatments. Addiction, 97, 155-167.

Davey, G. C. L. (1992) Classical conditioning and the acquisition of human fears and phobias: a review and synthesis of the literature. Advances in Behaviour Research and Therapy, 14, 2966.

Dawson, M. E. (1973) Can classical conditioning occur without contingency learning? A review and evaluation of the evidence. Psychophysiology, 10, 82-86.

Dawson, M. E. \& Schell, A. M. (1987) The role of 'controlled' and 'automatic' cognitive processes in human autonomic classical conditioning. In: Davey, G. C. L., ed. Cognitive Processes and Pavlovian Conditioning in Humans, pp. Chichester: John Wiley.

Dols, M., van den Hout, M., Kindt, M. \& Willems, B. (2002) The urge to smoke depends on the expectation of smoking. Addiction, 97, 87-93.

Dols, M., Willems, B. W., van den Hout, M. \& Bittoun, R. (2000) Smokers can learn to influence their urge to smoke. Addictive Behaviors, 25, 103-108. 
Droungas, A., Ehrman, R. N., Childress, A. R. \& O’Brien, C. P. (1995) Effect of smoking cues and cigarette availability on craving and smoking behavior. Addictive Behaviors, 20, 657673.

Drummond, D. C. (2000) What does cue-reactivity have to offer clinical research? Addiction, 95, S129-S144.

Drummond, D. C., Cooper, T. \& Glautier, S. P. (1990) Conditioned learning in alcohol dependence: implications for cue exposure treatment. British Journal of Addiction, 85, 725-743.

Drummond, D. C. \& Glautier, S. (1994) A controlled trial of cue exposure treatment in alcohol dependence. Journal of Consulting and Clinical Psychology, 62, 809-817.

Drummond, D. C., Litten, R. Z., Lowman, C. \& Hunt, W. A. (2000) Craving research: future directions. Addiction, 95, S247-S255.

Field, M. \& Duka, T. (2001) Smoking expectancy mediates the conditioned responses to arbitrary smoking cues. Behavioural Pharmacology, 12, 183-194.

Franken, I. H. A., de Haan, H. A., van der Meer, C. W., Haffmans, P. M. J. \& Hendriks, V. M. (1999) Cue reactivitity and effects of cue exposure in abstinent posttreatment drug users. Journal of Substance Abuse Treatment, 16, 81-85.

Havermans, R. C. \& Jansen, A. T. M. (2003) Increasing the efficacy of cue exposure treatment in preventing relapse of addictive behavior. Addictive Behaviors, 28, 989-994.

Heatherton, T. F., Kozlowski, L. T., Frecker, R. C. \& Fagerström, K. (1991) The Fagerström Test for Nicotine Dependence: a revision of the Fagerström Tolerance Questionnaire. British Journal of Addiction, 86, 1119-1127.

Juliano, L. M. \& Brandon, T. H. (1998) Reactivity to instructed smoking availability and environmental cues: evidence with urge and reaction time. Experimental and Clinical Psychopharmacology, 6, 45-53.

Lavez, A. B., Herzog, T. A., Thaddeus, A. \& Brandon, T. H. (1999) Classical conditioning of environmental cues to cigarette smoking. Experimental and Clinical Psychopharmacology, 7, 56-63.

Lee, N. K. \& Oei, T. P. S. (1993) Exposure and response prevention in anxiety disorders: implication for treatment and relapse prevention in problem drinkers. Clinical Psychological Review, 13, 619-632.
Lovibond, P. F. (2003) Causal beliefs and conditioned responses: retrospective revaluation induced by experience and by instruction. Journal of Experimental Psychology, Learning Memery and Cognition, 29, 97-106.

Marlatt, G. A. (1985) Situational determinants of relapse and skill-training interventions. In: Marlatt, G. A. \& Gordon, J. R., eds. Relapse Prevention, pp. 71-127. New York: Guilford Press.

Monti, P. M., Rohsenow, D. J., Rubonis, A. V., Niaura, R. S., Sirota, A. D., Colby, S. M., Goddard, P. \& Abrams, D. B. (1993) Cue exposure with coping skill treatment for male alcoholics: a preliminary investigation. Journal of Consulting and Clinical Psychology, 61, 1011-1019.

Niaura, R., Abrams, D. B., Shadel, W. G., Rohsenow, D. J., Monti, P. M. \& Sirota, A. D. (1999) Cue exposure treatment for smoking relapse prevention: a controlled clinical trial. Addiction, 94, 685-695.

Niaura, R., Rohsenow, D. J., Binnkoff, J. A., Monti, P. M., Pedrazza, M. \& Abrams, D. B. (1988) Relevance of cue reactivity to understanding alcohol and smoking relapse. Journal of Abnormal Psychology, 97, 133-152.

O'Brien, C. P., Childress, A. R., McLellan, T. \& Ehrman, R. (1990) Integrating systematic cue exposure with standard treatment in recovering drug dependent patients. Addictive Behaviors, 15, 355-365.

Powell, J., Gray, J. \& Bradley, B. P. (1993) Subjective craving for opiates: evaluation of a cue exposure protocol for use with detoxified opiate addicts. British Journal of Clinical Psychology, $32,39-53$.

Powell, J. (1995) Conditioned responses to drug-related stimuli: is context crucial? Addiction, 90, 1089-1095.

Staiger, P. K., Greeley, J. D. \& Wallace, S. D. (1999) Alcohol exposure therapy: generalization and changes in responsivity. Drug and Alcohol Dependence, 57, 29-40.

Tiffany, S. T. (1990) A cognitive model of urges and drug-use behavior: role of automatic and non-automatic processes. Psychological Review, 97, 147-168.

Wertz, J. M. \& Sayette, M. A. (2001) A review of the effects of perceived drug use opportunity on self-reported urge. Experimental and Clinical Psychopharmacology, 9, 3-13. 